\title{
CARACTERIZAÇÃO DE MUDANÇAS CLIMÁTICAS NA CIDADE DO RECIFE UTILIZANDO SÉRIES TEMPORAIS
}

\author{
ROCHA, João Vitaliano de Carvalho - vitaliano2012@gmail.com \\ Universidade Tiradentes - FACIPE/UNIT \\ SANTOS, Valdemir Alexandre dos - valdemir.alexandre@hotmail.com \\ Universidade Tiradentes - FACIPE/UNIT
}

\begin{abstract}
RESUMO: Foi realizada uma análise de parâmetros meteorológicos da Cidade do Recife, correspondente a um período de 19 anos (1990 a 2009), utilizando a metodologia estatística de séries temporais. Os dados foram fornecidos pelo Instituto Nacional de Meteorologia (INMET), do Ministério da Agricultura, Pecuária e Abastecimento (MAPA), no período de janeiro de 1989 a dezembro de 2009, permitindo a comparação e escolha entre modelos estatísticos, tendo o modelo das médias móveis apresentado melhor desempenho na previsão de parâmetros meteorológicos. As temperaturas máximas registradas entre os anos de 2003 a 2009, nos meses novembro, dezembro, janeiro, fevereiro, março e abril, variaram entre $30^{\circ} \mathrm{C}$ e $31,9^{\circ} \mathrm{C}$, valores estes considerados acima da média climatológica.
\end{abstract}

Palavras- chaves: Parâmetros meteorológicos, Metodologia de Séries Temporais, Médias móveis, Modelagem estatística.

\section{CLIMATE CHANGES CHARACTERIZATION ON RECIFE/PE USING TIME SERIES}

ABSTRACT: An analysis was held of meteorological parameters of Recife City, correspondent to a period of 19 years ( 1990-2009), using the statistical method of time series. Data were provided by the National Institute of Meteorology ( INMET ), the Ministry of Agriculture, Livestock and Supply (MAPA ), from January 1990 to December 2009 , allowing for comparison and choice of statistical models, and the model of the medium movies presented better performance in predicting meteorological parameters . The maximum temperatures registered between the years 2003-2009, in the months November, December, January, February, March and April , ranged between $30^{\circ} \mathrm{C}$ and $31.9^{\circ} \mathrm{C}$, values considered above the climatological average.

Keys- words: Meteorological parameters, Time series methodology, Moving averages, Statistical modeling.

\section{INTRODUÇÃO}

Uma série temporal pode ser definida como um conjunto de observações de uma variável disposta, sequencialmente, no tempo. A variável é observada em pontos temporais discretos, usualmente equidistantes e, a análise de tal comportamento temporal envolve uma descrição do processo ou fenômeno que gera a sequência (BOX, 2008).

Dessa forma, o aumento do valor diário da concentração de materiais particulados no ar da cidade de São Paulo, o aumento no valor da temperatura máxima do Rio de Janeiro ou o índice pluviométrico da cidade do Recife no inverno são exemplos de variáveis quantitativas que mudam seu valor com o passar do tempo, que pode ter a unidade em horas, dias, mês, anos, de acordo com o objetivo do estudo (LATORRE, 2001).

De acordo com Soncin (2003) a análise de séries temporais é uma área da Estatística dedicada ao estudo de observações que apresentam dependência no tempo e surgem nas mais variadas áreas de aplicação, como: Medicina, 
Engenharia, Meteorologia, entre outras, e pode identificar a natureza do fenômeno representado pela sequência de observações, quando procura um padrão de comportamento, por prever a evolução futura da variável da série temporal e por rever as decisões tomadas com a possibilidade de repensar a planificação.

A tendência climática, segundo Tomé (2001) é entendida como uma alteração suave do clima, com acréscimo ou decréscimo nos valores médios das variáveis analisadas, no período de registro, e, as séries temporais são analisadas a partir de seus principais movimentos descritos como: tendência, ciclo, sazonalidade e variáveis aleatórias (OLIVEIRA, 2008).

O clima pode ser definido como o conjunto de condições meteorológicas, entre elas: temperatura, umidade, chuva, pressão e ventos que apresentam características comuns em uma determinada região (COSTA, 2009).

Dantas (2008) informa que as características atmosféricas mudam de lugar para lugar e, com o decorrer do tempo, em qualquer lugar, e em escalas de tempo que variam de segundos até centenas de anos.

Santos (2009) concluiu que a coluna de vapor de água total aumentou os oceanos em 1,2 +/- 0,3\% por década, o que corresponde a 95\% de limites de probabilidade, desde 1988 até 2004 tendo este fenômeno, relação com temperaturas mais altas, tanto terrestres como oceânicas.

Há indícios de que as precipitações estejam se tornando mais fortes e frequentes em muitas regiões da Terra a partir de 1950, possivelmente, devido a um aumento de intensidade da atividade ciclônica tropical Atlântico Norte (SANTOS, 2009).

Entre as causas de alterações significativas na temperatura global estão as variações da temperatura da superfície do mar, variações da circulação atmosférica, alterações na frequência de ocorrência de eventos El NiñoOscilação Sul (ENOS). O evento El Niño de 1997/1998 foi considerado o evento mis intenso do século passado produziu anomalias de temperatura do ar, cerca de $+0,8^{\circ} \mathrm{C}$, enquanto o La Niña de $1984 / 1985$, um resfriamento de $-0,5^{\circ} \mathrm{C}$ (KUCHARSKI, 2008).

Molion (2002) observou que as anomalias apresentaram uma tendência positiva, de cerca de $+0,37^{\circ} \mathrm{C}$, durante o período da fase quente da Oscilação Decadal do Pacífico (ODP) entre os anos de 1925 e 1946 e durante a ocorrência dos eventos La Niña, as anomalias da temperatura média global apresentaram uma tendência negativa, com um decréscimo aproximado de $-0,14^{\circ} \mathrm{C}$ entre os anos de 1947 e 1976.

Desde 1970 a precipitação tende a ficar acima da média do século XX, com média de cerca de $5 \%$ superior ao anterior de 70 anos (MARENGO, 2007). O objetivo do presente trabalho foi analisar o comportamento do clima na cidade do Recife, durante as décadas de 1990 a 2009, com auxílio da metodologia de séries temporais que permitiram uma interpretação sobre as tendências e sazonalidades aplicada a dados de temperatura máxima média mensal, temperatura média compensada mensal, temperatura mínima média mensal, umidade relativa do ar e índice pluviométrico para identificação de oscilações sazonais. 


\section{MATERIAL E MÉTODOS}

\subsection{CARACTERÍSTICAS METEOROLÓgICAS}

Inserida na área de contato entre a Serra do Espinhaço e a Depressão O Recife, região escolhida para a realização de análise de dados meteorológicos proposta por este trabalho é a capital do Estado de Pernambuco, e localiza-se às margens do Oceano Atlântico. Tem um clima tropical, com alta umidade relativa do ar. Apresenta temperatura máxima de $30^{\circ} \mathrm{C}$ e mínima de $20^{\circ} \mathrm{C}$ tendo como média anual $25^{\circ} \mathrm{C}$ com alto índice de pluviosidade. Tem uma área de $218 \mathrm{~km} 2 \mathrm{e}$ população de 1,53 milhões de pessoas, ou 3,73 milhões contando com a área metropolitana (SEPLAN, 2010).

Efeitos de variações espacial e temporal numa infraestrutura física e urbana e a vegetação são responsáveis basicamente pelas variações nos efeitos de urbanização sobre a umidade em uma região (KUCHARSKI; POLZIN; HASTENRATH, 2008). Entretanto, a redução da cobertura vegetal e a quantidade de vapor retido sobre a superfície são os principais fatores responsáveis pela baixa umidade dentro das cidades. A tendência de aquecimento observada nos últimos anos, que tem modificado a temperatura média em escala global e hemisférica, pode estar relacionada com o crescimento urbano ao redor das estações meteorológicas, visto que os efeitos de ilha de calor produzem uma variação na temperatura, similar ao relacionamento com o aumento do efeito estufa dos gases na atmosfera (UVO et al, 1998)..

\subsection{PARÂMETROS METEOROLÓGICAS UTILIZADOS}

Os parâmetros meteorológicos de: precipitação total $(\mathrm{mm})$, umidade relativa do ar (\%), temperatura média compensada mensal, temperatura média mínima mensal e temperatura média máxima mensal. Foram obtidos da Estação Climatológica Principal de Recife, localizada no bairro de Curado, Recife Pernambuco (Latitude: $08^{\circ} 03^{\prime} \mathrm{S}$; Longitude: $034^{\circ} 57^{\prime} \mathrm{W}$; Altitude: $10 \mathrm{~m}$ ), gentilmente cedidos pelo Instituto Nacional de Meteorologia (INMET), do Ministério da Agricultura, Pecuária e Abastecimento (MAPA). Os referidos dados abrangem o período de janeiro de 1990 a dezembro de 2009 sendo, portanto, uma série de dados com 19 anos de duração

A heterogeneidade de repartição temporal se constitui numa característica básica do regime pluviométrico da região nordeste do Brasil, embora seja mais atenuada na faixa litorânea e bem mais destacada no Sertão. Assim sendo, alguns anos caracterizam-se por uma pluviosidade excessiva, enquanto em outros anos a chuva ocorre de forma escassa, com situações de estiagem, por vezes dentro de uma condição extremamente prolongada (FILHO et al, 2002).

A umidade relativa do ar é tomada em referência ao ar atmosférico, e este por sua vez é influenciado tanto pela temperatura, quanto pela pluviometria. A umidade relativa do ar pode ser definida então como a relação entre a pressão do vapor d'água na atmosfera e a pressão desse vapor saturado à mesma temperatura. Isso significa que a umidade relativa é uma razão, e assim expressa em porcentagem. A cidade de Recife apresenta valores muito 
elevados para a umidade relativa do ar, onde a influência deverá estar condicionada às correntes eólicas advindas do litoral.

A temperatura é o parâmetro climático mais estável, com relação aos demais. As suas flutuações ocorrem, nos diferentes horários de observação (12:00, 18:00 e 24:00 TMG - Tempo Médio de Greenwich); nas observações sequenciais pouco mudam nos horários comuns. Para ter uma visão mais realista deste parâmetro às analises são feitas em seus extremos (temperaturas máxima e mínima); observadas nos horários de 24:00 e 12:00 TMG, e a média compensada é obtida pela relação a seguir:

$$
\mathrm{T}_{\mathrm{MC}}=\frac{\mathrm{T}_{12}+2 \cdot \mathrm{T}_{24}+\mathrm{T}_{\text {Máx }}+\mathrm{T}_{\mathrm{Min}}}{5}
$$

Em que:

$\mathrm{T}_{12}$ - temperatura das 12 horas TMG

$\mathrm{T}_{24}$ - temperatura das 24 horas TMG

TMáx - temperatura máxima diária

TMín - temperatura mínima diária

De posse da temperatura média compensada mensal, podem-se basear os estudos subsequentes num único parâmetro de temperatura, que em sua definição denota um menor grau de incerteza quanto às médias simples.

\section{Procedimentos de análise}

\section{Gráfico de linha}

A primeira etapa para a análise de uma série temporal é dispô-la em uma planilha de forma que facilite a obtenção de um gráfico de linha (MCCULLUOGH; HEISER, 2008). Num gráfico desse tipo, no eixo horizontal são colocados os períodos da série e, no eixo vertical, os valores da série. Os pontos são ligados por linhas para facilitar uma visualização do comportamento.

\section{Obtenção de tendência para a série}

\section{Modelo linear}

Para identificar a tendência numa série pode-se adicionar uma linha de tendência, por exemplo, linear, ao gráfico de linhas da série temporal, juntamente com a equação correspondente. Em seguida, procede-se de forma a se obter uma linha de tendência por ajuste de um modelo matemático (linear, por exemplo) aos dados experimentais, para a série em análise. Pode-se então observar uma inclinação positiva ou negativa da linha de tendência dos valores da série em análise.

\section{Média Móvel Simples}

Ao se optar por, uma média móvel para se caracterizar a tendência de uma série, caminha-se na direção de um aspecto crítico que é definir a sua ordem, ou quantos períodos serão englobados por vez, e obter valores numéricos para a respectiva tendência da série. Ao lidar com dados anuais pode-se escolher um número ímpar de períodos, o que facilita o processo por 
eliminar a necessidade de centrar as médias (MORETTIN, 2004). Ainda, segundo o mesmo autor, no caso em questão, os dados meteorológicos foram registrados mensalmente e isso obriga a calcular médias móveis de 12 períodos, uma vez que há 12 meses num ano, para que seja removido o efeito das variações sazonais. Como o número de períodos é par, é preciso centrar as médias.

\section{Média Móvel com Suavização Exponencial}

Outra forma de obter a tendência é através do ajuste por média móvel do tipo exponencial. Consiste em aplicar uma média móvel, exponencialmente ponderada, por uma constante de regularização W (BOX, 1994), a qual varia entre 0 e 1 . Quanto mais próxima de 1, mais o ajuste exponencial acompanhará a série original, e quanto mais próxima de zero, mais o ajuste refletirá o comportamento de longo prazo. Como no presente caso deseja-se caracterizar a tendência da série, pode-se utilizar uma constante $W=0,1$ e proceder o ajuste através da equação:

$$
E_{i}=W \cdot Y_{i}+(1-W) \cdot E_{i-1}
$$

Em que:

i - um período de tempo qualquer;

Yi - valor da série original no período i;

Ei - valor da série exponencialmente ajustada no período i; anterior);

Ei-1 - valor da série exponencialmente ajustada no período i-1 (período

W - constante de regularização ou coeficiente de ajuste $(0<W<1)$;

Considera-se que o primeiro valor da série original será igual ao primeiro valor ajustado, isto significa que o ajuste realmente começa a partir do segundo período da série. finalidades:

A componente tendência pode ser utilizada posteriormente para duas

- removida para que se possam obter outras componentes da série temporal (supondo um modelo clássico) e;

- utilizada para fazer previsões para períodos futuros.

\section{Índices de sazonalidade}

As variações sazonais são aquelas que ocorrem regularmente no período de um ano. Nas séries meteorológicas de temperatura do ar normalmente a temperatura é maior no verão e menor no inverno o que mostra claramente uma variação de período anual. Nos estudos climatológicos a componente sazonal das séries temporais é muito intensa, principalmente na regiões extratropicais. É conveniente utilizar procedimentos para avaliar a sazonalidade e métodos de previsão que considerem o efeito das flutuações sazonais sobre as variáveis, pois quanto mais informações se tiverem sobre o comportamento dessas variáveis, mais acurada será a previsão (REBOITA, 2005). Ainda, segundo o mesmo autor, o número de índices é essencial, pois determinará a ordem das médias móveis que serão calculadas para obter os índices sazonais, 
supondo o uso do método da razão para a média móvel. Além disso, dependendo da escolha por um modelo aditivo ou multiplicativo os procedimentos serão diferentes. No caso, por exemplo, da temperatura média compensada mensal, a série foi registrada mensalmente e, portanto, precisa-se calcular 12 índices, e verificar se a influência da sazonalidade é significativa. Como isso realmente ocorria, a componente sazonal foi incluída no modelo da série que será usado para fazer previsões. Nesse caso, a primeira etapa foi calcular as médias móveis de 12 períodos centradas. No caso em questão, tais operações foram feitas para os períodos da série que apresentaram médias móveis calculadas, ou seja, foram excluídos os 6 primeiros e os 6 últimos. No modelo aditivo é preciso inicialmente calcular as médias aritméticas simples dos índices de cada mês. Calculam-se então as médias progressivamente, selecionando os índices sazonais referentes aos meses de janeiro, fevereiro, março, etc. Há 19 índices para cada mês: a série tem 20 anos (240 meses), portanto 19 janeiros, 19 fevereiros, 19 marços, etc. Contudo, devido ao processo de obtenção das médias móveis de 2 períodos centradas, 12 meses foram descartados, resultando que sobraram 18 janeiros, 18 fevereiros, 18 marços, etc. No modelo aditivo há influência da sazonalidade se os índices sazonais forem substancialmente diferentes de zero.

\section{RESULTADOS E DISCUSSÃO}

\subsection{TEMPERATURA MÉDIA COMPENSADA MENSAL (TMCM)}

A Figura 1 corresponde à evolução temporal das médias mensais de temperatura compensada do ar. Observa-se no referido gráfico que a linha de tendência obtida tem inclinação positiva, demonstrando que o valor de temperatura média compensada tem aumentado no período de análise dos dados.

As Figuras 2 e 3 correspondem aos gráficos das médias móveis simples e exponencial dos dados. Observa-se, ao longo de toda a série, que os valores de temperatura média compensada obtida das médias móveis oscilam entre 23 e $28{ }^{\circ} \mathrm{C}$, flutuando em torno de $26^{\circ} \mathrm{C}$, que parece ser o comportamento de longo prazo, tal como foi concluído ao se analisar a tendência linear. Além disso, podese observar outro comportamento muito interessante através das médias móveis:

- observam-se os "altos e baixos" das médias móveis, em relação ao nível de $26^{\circ} \mathrm{C}$;

- aproximadamente até o período 36 os valores estão abaixo de 26 ${ }^{\circ} C^{\prime}$ (com exceção dos 4 primeiros períodos para o modelo a média móvel exponencial;

- começam então a crescer e vão até o período 111, quando oscilam daí por diante muito próximo de $26^{\circ} \mathrm{C}$ e; mensal

- em média existe um aumento na temperatura média compensada 


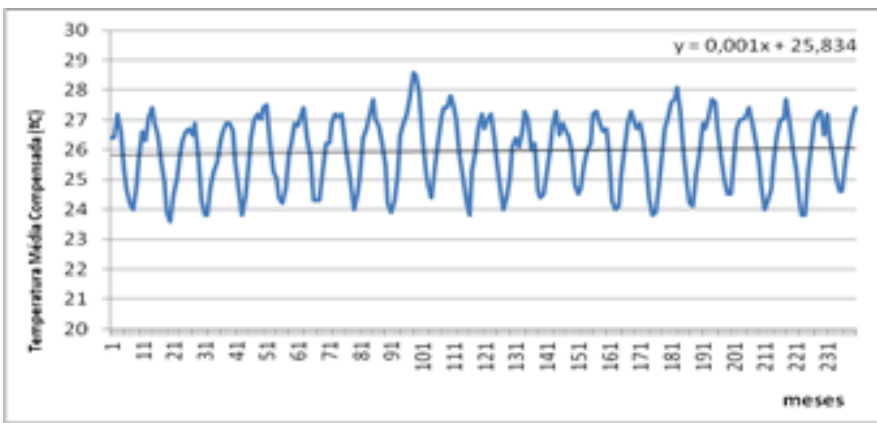

Figura 1 - Oscilações da TMCM em Recife (1990-2009) e respectiva linha de tendência obtida por regressão linear

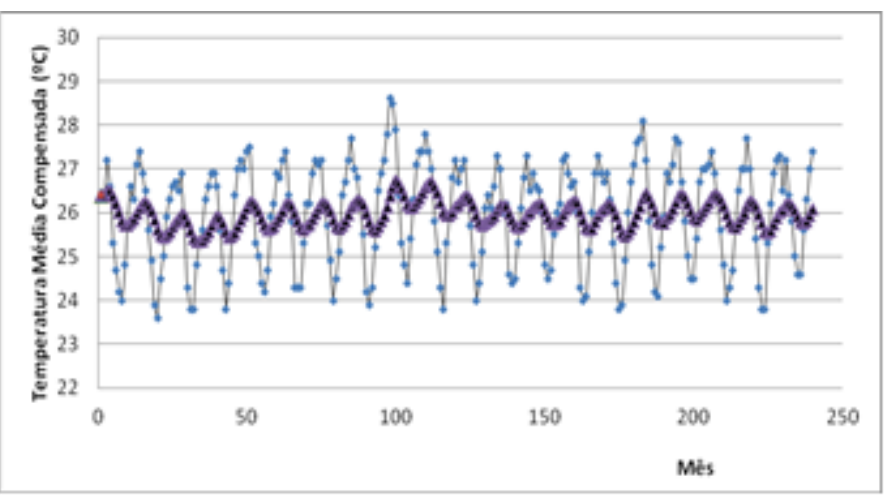

Figura 2 - Oscilações da TMCM em Recife (1990-2009) e respectiva linha de tendência por médias móveis simples

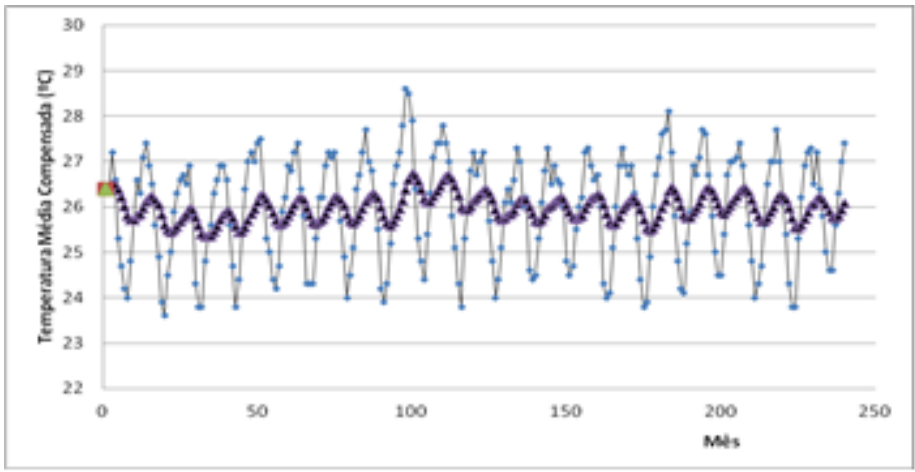

Figura 3 - Oscilações da TMCM em Recife (1990-2009) e respectiva linha de tendência por média móvel exponencial

Observa-se ainda (Tabela 1), com auxílio de índices sazonais, que nos meses de janeiro a março, ocorre uma anomalia em que há aumento na temperatura, que chega a $1,3{ }^{\circ} \mathrm{C}$, em fevereiro, em relação à média mensal. $\mathrm{A}$ partir de abril inicia-se uma queda substancial, havendo uma redução de quase $2{ }^{\circ} \mathrm{C}\left(-1,77^{\circ} \mathrm{C}\right)$ em agosto em relação à média mensal caracterizando uma anomalia negativa. 
A Tabela 2 apresenta diferenças entre as médias obtidas das duas décadas estudadas, podendo-se observar valores positivos entre 0,1 e 0,3 para os meses de maio, julho, agosto, setembro, outubro, novembro e dezembro, valor 0,0 para os meses de janeiro e junho e negativos para os meses de fevereiro, março e abril.

Tabela 1 - Representação das Médias e Índices Sazonais de TMCM ( ${ }^{\circ} \mathrm{C}$ ) em Recife (1990-2009)

\begin{tabular}{lcc}
\hline Mês & Média Sazonal & Índices Sazonal \\
\hline Janeiro & 1,113421053 & 1,117017544 \\
Fevereiro & 1,301894737 & 1,305491228 \\
Março & 1,211421053 & 1,215017544 \\
Abril & 0,594631579 & 0,59822807 \\
Maio & $-0,216894737$ & $-0,213298246$ \\
Junho & $-1,249473684$ & $-1,245877193$ \\
Julho & $-1,77$ & $-1,766403509$ \\
Agosto & $-1,781526316$ & -1777929825 \\
Setembro & $-0,877263158$ & $-0,873666667$ \\
Outubro & 0,005947368 & 0,00954386 \\
Novembro & 0,626 & 0,629596491 \\
Dezembro & 0,998684211 & 1,002280702 \\
Soma & $-0,043157895$ & 0,00 \\
Excesso & $-0,003596491$ & \\
\hline
\end{tabular}

Tabela 2 - Diferenças de TMCM obtidas entre as duas décadas do período 1990 a 2009

\begin{tabular}{lllllllllllll}
\hline Década & Jan & Fev & Mar & Abr & Mai & Jun & Jul & Ago & Set & Out & Nov & Dez \\
\hline Primeira & 27,0 & 27,3 & 27,2 & 26,6 & 25,7 & 24,7 & 24,1 & 24,1 & 25,0 & 25,9 & 26,5 & 26,9 \\
Segunda & 27,0 & 27,2 & 27,1 & 26,5 & 25,8 & 24,7 & 24,2 & 24,3 & 25,2 & 26,0 & 26,7 & 27,0 \\
Diferença & 0,0 & $-0,1$ & $-0,1$ & $-0,1$ & 0,1 & 0,0 & 0,1 & 0,2 & 0,2 & 0,1 & 0,2 & 0,1 \\
\hline
\end{tabular}

\section{Temperatura Máxima Média Mensal (TMáxMM)}

A Figura 4 exibe a linha de tendência positiva para o período estudado em relação à temperatura máxima média mensal, por regressão linear. Observe-se que a linha inicia-se no valor abaixo de $30^{\circ} \mathrm{C}$ e ascende até a linha dos $30^{\circ} \mathrm{C}$.

As Figuras 5 e 6, que corresponde aos gráficos ajustados pelas médias móveis simples e exponencial, respectivamente, observando-se o comportamento da linha, na maioria dos períodos, próximo ao valor $30^{\circ} \mathrm{C}$, principalmente na segunda década. 
A Tabela 3 mostra a diferença entre as médias mensais da normal climatológica do período (1961 a 1990) e do segundo período (1990 a 2009). É possível observar que os valores foram positivos na maioria dos meses do último período caracterizando um aumento da temperatura para a região em estudo.

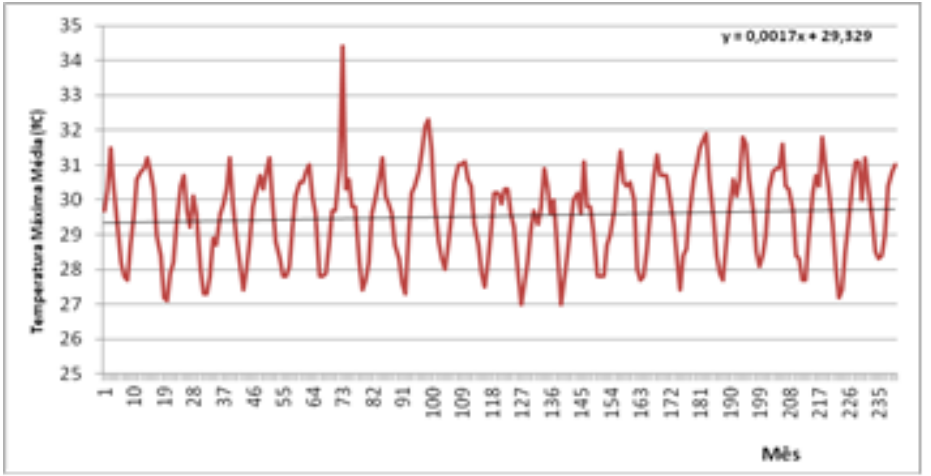

Figura 4 - Oscilações da TMáxMM em Recife (1990-2009) e respectiva linha de tendência obtida por regressão linear

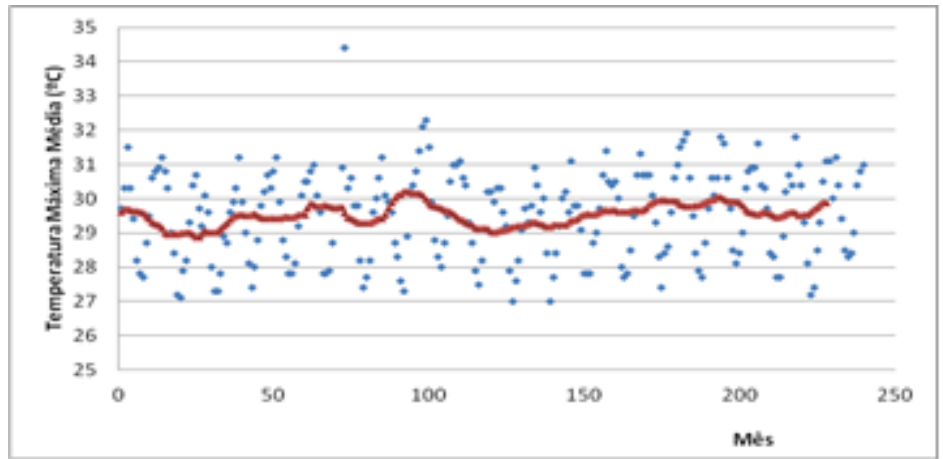

Figura 5 - Oscilações da TMáxMM em Recife (1990-2009) e respectiva linha de tendência por média móvel simples

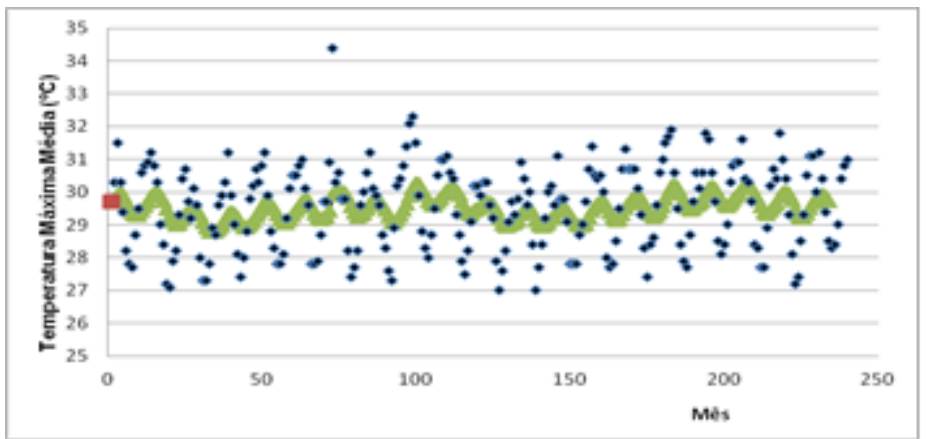

Figura 6 - Oscilações da TMáxMM em Recife (1990-2009) e respectiva linha de tendência por média móvel exponencial

A Tabela 3 corresponde à média das temperaturas máximas mensais observadas na primeira década (1990/1999) e na segunda década (2000/2009). A diferença mostra a evolução da temperatura máxima de uma década em 
relação à outra. Os valores positivos mostram que a segunda década foi mais quente que a primeira em 9 meses.

Tabela 3 - Temperatura máxima: diferença entre as médias mensais por década do período 1990 a 2009

\begin{tabular}{lllllllllllll}
\hline Década & Jan & Fev & Mar & Abr & Mai & Jun & Jul & Ago & Set & Out & Nov & Dez \\
\hline Primeira & 30,6 & 30,7 & 30,7 & 30,2 & 29,3 & 25,4 & 27,6 & 27,6 & 28,4 & 29,4 & 29,9 & 30,5 \\
Segunda & 30,6 & 30,9 & 30,8 & 30,2 & 29,5 & 25,7 & 27,8 & 27,9 & 28,5 & 29,5 & 30,4 & 30,6 \\
Diferença & 0,0 & 0,2 & 0,1 & 0,0 & 0,2 & 0,2 & 0,2 & 0,3 & 0,1 & 0,1 & 0,5 & 0,1 \\
\hline
\end{tabular}

A Tabela 4 correspondente aos índices sazonais de temperatura máxima média mensal e observa-se que há seis meses com valores positivos destacando o mês de fevereiro com $(+1,29)$ valor considerado acima da média climatológica, e seis meses com valores negativos, dos quais, o mês de agosto registrou o menor índice $(-1,77)$ abaixo da média climatológica caracterizando uma anomalia de temperatura.

Tabela 4 - Valores das Médias e Índices Sazonais de Temperatura Máxima Média Mensal $\left({ }^{\circ} \mathrm{C}\right)$ em Recife de 1990 a 2009

\begin{tabular}{lcc}
\hline \multicolumn{1}{c}{ Aditivo } & Média Sazonal & Índice Sazonal \\
\hline Janeiro & 1,253263158 & 1,208570176 \\
Fevereiro & 1,336473684 & 1,291780702 \\
Março & 1,235473684 & 1,190780702 \\
Abril & 0,713421053 & 0,668728071 \\
Maio & $-0,003368421$ & $-0,048061403$ \\
Junho & $-1,099105263$ & $-1,143798245$ \\
Julho & $-1,200105263$ & $-1,244798245$ \\
Agosto & $-1,727421053$ & $-1,772114035$ \\
Setembro & $-1,107368421$ & $-1,152061403$ \\
Outubro & $-0,208368421$ & $-0,253061403$ \\
Novembro & 0,438 & 0,393307018 \\
Dezembro & 0,905421053 & 0,860728071 \\
Soma & 0,536315789 & 0,0 \\
Excesso & 0,044692982 & \\
\hline
\end{tabular}

\section{Temperatura mínima média mensal (TMínMM)}

A Figura 6 apresenta o gráfico de temperatura mínima com a linha de tendência positiva, obtida por regressão linear, evidenciando desta forma um aquecimento da região em estudo nas duas últimas décadas.

As Figuras 7, 8 e 9 mostram os gráficos obtidos pela regressão linear, média móvel simples e exponencial, respectivamente, onde se podem observar os 
comportamentos ascendente ao longo da série em quase todos os períodos, caracterizando uma anomalia de aumento da temperatura mínima.

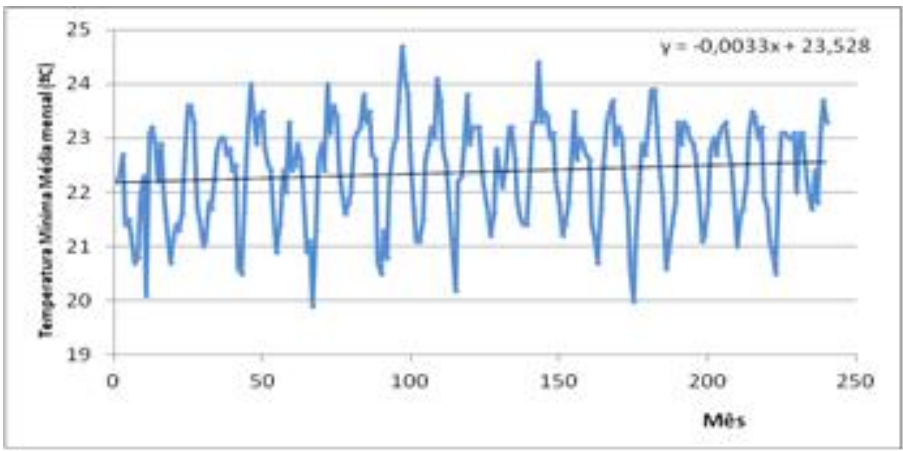

Figura 7 - Oscilações da TMinMM em Recife (1990-2009) e respectiva linha de tendência obtida por regressão linear

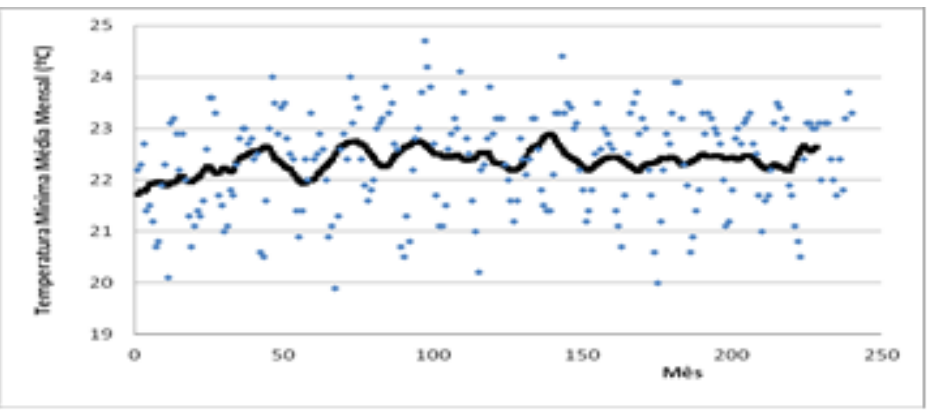

Figura 8 - Oscilações da TMínMM em Recife (1990-2009) e respectiva linha de tendência por média móvel simples

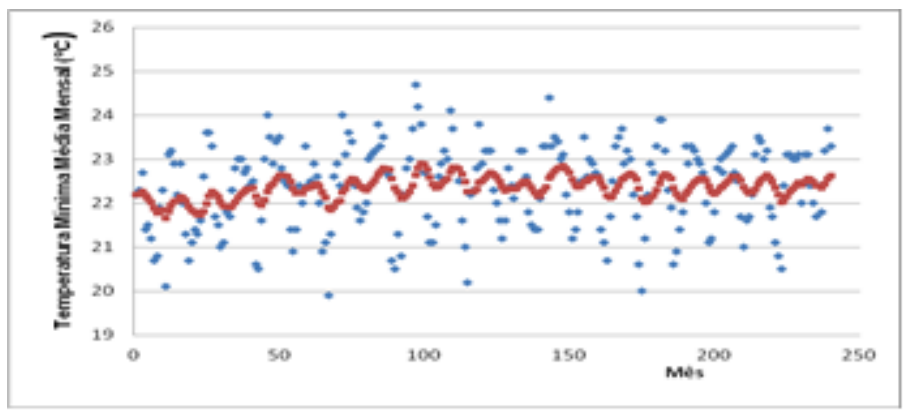

Figura 9 - Oscilações da TMínMM em Recife (1990-2009) e respectiva linha de tendência por média móvel exponencial

A dinâmica populacional e valoração do uso do solo são bem diversas ao $\mathrm{Na}$ Tabela 5 pode-se observar que os índices sazonais dos meses de junho, julho, agosto, setembro e outubro, foram negativos com destaque para o mês de agosto com $(-1,46)$ abaixo da média. Os valores negativos observados nos meses de agosto, setembro e outubro caracterizam uma possível alteração climática para a região em estudo. Os meses de novembro a maio apresentaram valores positivos considerados acima da média. A Tabela 6 mostra que o segundo semestre da segunda década (2000 a 2009) foi mais aquecido do que a primeira (1990 a 1999). 
Tabela 5 - Valores das médias e Índices sazonais de temperatura mínima mensal em Recife (1990 - 2009)

\begin{tabular}{lcc}
\hline Mês & Média Sazonal & Índice Sazonal \\
\hline Janeiro & 0,752678947 & 0,739835965 \\
Fevereiro & 0,940252632 & 0,92740965 \\
Março & 0,875194737 & 0,862351755 \\
Abril & 0,494347368 & 0,481504386 \\
Maio & 0,034552632 & 0,02170965 \\
Junho & $-0,646294737$ & $-0,659137719$ \\
Julho & $-1,253457895$ & $-1,266300877$ \\
Agosto & $-1,450094737$ & $-1,462937719$ \\
Setembro & $-0,741468421$ & $-0,754311403$ \\
Outubro & $-0,001263158$ & $-0,01410614$ \\
Novembro & 0,454731579 & 0,441888597 \\
Dezembro & 0,694936842 & 0,68209386 \\
Soma & 0,154115789 & 0,0 \\
Excesso & 0,012842982 & \\
\hline
\end{tabular}

Tabela 6 - Temperatura mínima: diferença entre as médias mensais por década do período 1990 a 2009

\begin{tabular}{lllllllllllll}
\hline Década & Jan & Fev & Mar & Abr & Mai & Jun & Jul & Ago & Set & Out & Nov & Dez \\
\hline Primeira & 23,1 & 23,3 & 23,3 & 22,9 & 22,3 & 21,6 & 21,0 & 20,8 & 21,4 & 22,3 & 22,6 & 22,7 \\
Segunda & 23,1 & 23,2 & 23,2 & 22,8 & 22,4 & 21,8 & 21,2 & 21,0 & 21,8 & 22,5 & 23,0 & 23,2 \\
Diferença & 0,0 & 0,1 & $-0,1$ & $-0,1$ & 0,1 & 0,2 & 0,2 & 0,2 & 0,4 & 0,2 & 0,4 & 0,5 \\
\hline
\end{tabular}

\section{Precipitação Média Mensal}

A Figura 9 mostra a linha de tendência positiva observada no período de janeiro de 1990 a dezembro de 2009. A precipitação atingiu picos maiores durante os meses de abril, maio, junho e julho dos quais o mês de junho de 2005 registrou o valor máximo de $709(\mathrm{~mm})$ sendo considerado o maior da série e o mínimo de $8,7(\mathrm{~mm})$, o menor da série, no mês de novembro do mesmo ano. O ano de 1998, considerado mais quente da série em estudo apresentou Índice Pluviométrico Máximo de 277,8 e mínimo de 15,8 (mm). O trimestre que apresentou menor núcleo de precipitação acumulada foi o último tendo os meses de outubro e novembro registrado 8,7 (mm) nos anos de 2005 e 2006 respectivamente. 


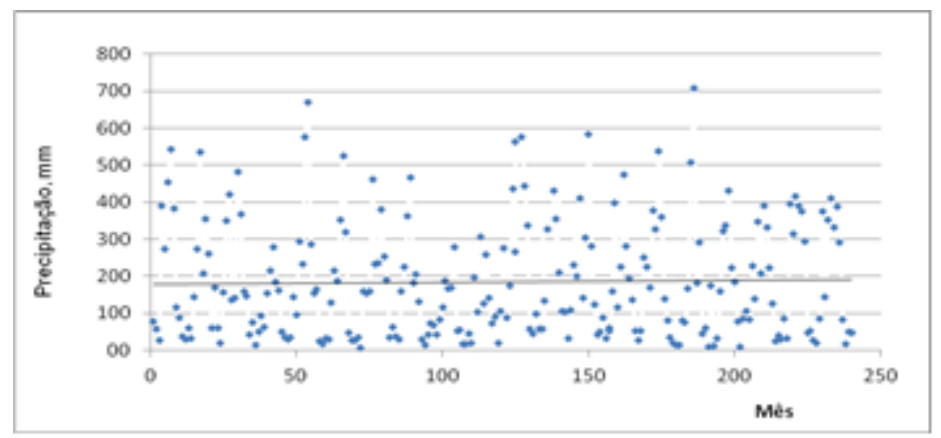

Figura 10 - PMM em Recife (1990-2009) e linha de tendência obtida por regressão linear

As Figuras 10 , 11 e 12 correspondem aos modelos de precipitação média mensal, obtidos por regressão linear, médias móveis simples e exponencial, respectivamente. Pode-se observar que entre os períodos de 11 a 18, 28 a 50, 58 a 73, 83 a 121, 133 a 138, 151 a 163, 175 a 187 e 192 a 216 a precipitação acumulada permaneceu abaixo da média histórica.

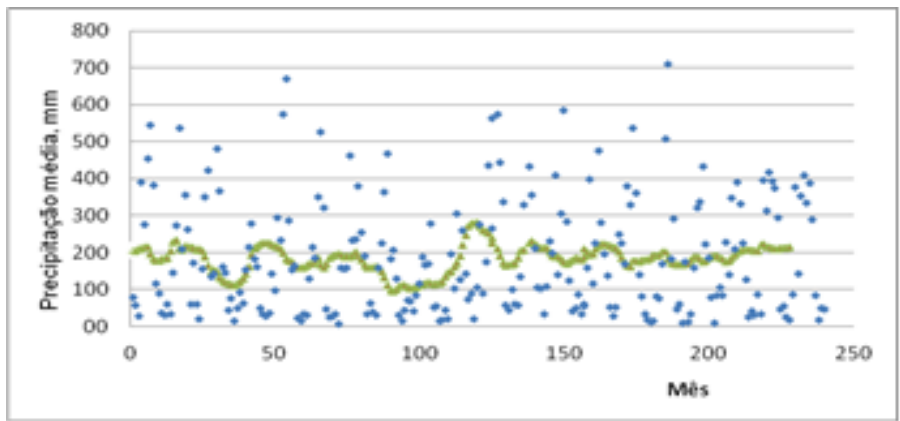

Figura 11 - Oscilações da precipitação média em Recife (1990-2009) e respectiva linha de tendência por média móvel simples

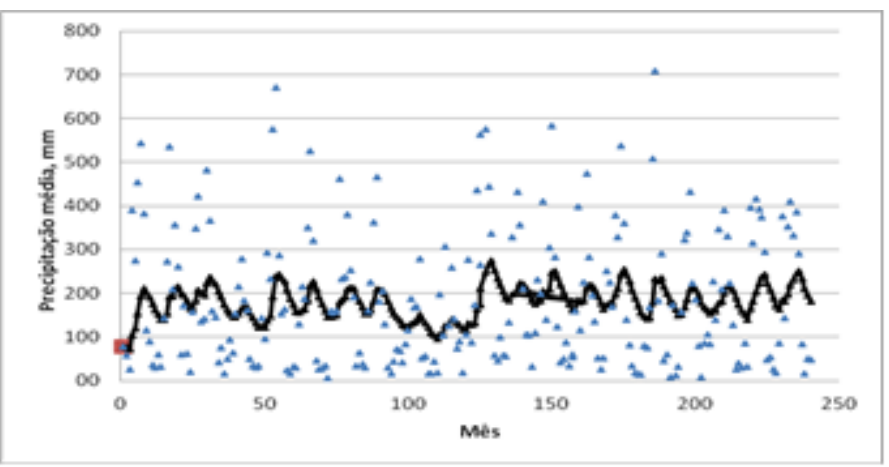

Figura 12 - Oscilações da precipitação média em Recife (1990-2009) e respectiva linha de tendência por média móvel exponencial

A Tabela 7 mostra a representação das médias e índices sazonais de Precipitação (mm) em Recife de 1990 a 2009. Nota-se que os índices sazonais apresentaram seis (06) meses com valores negativos tendo o mês de novembro registrado o maior valor abaixo da média $(-143,1)$ e seis meses com valores positivos tendo destaque o mês de junho com $(+223,9)$, acima da média. 
Os meses de abril, maio, junho e julho de 2005 a 2009 foram marcados por chuvas moderadas a fortes em toda a Região Metropolitana do Recife. A variabilidade das chuvas na região metropolitana na época chuvosa é diretamente influenciada pelas temperaturas das superfícies de ambos os oceanos tropicais, Atlântico e Pacífico, que modulam o posicionamento da Zona de Convergência Intertropical, que é o principal sistema causador de precipitação do Nordeste (BEZERRA, 2008).

Tabela 7 - Valores das Médias e Índices Sazonais de Precipitação (mm) em Recife (1990 a 2009).

\begin{tabular}{lcc}
\hline Aditivo & Média Sazonal & Índice Sazonal \\
\hline Janeiro & $-82,9$ & $-82,7$ \\
Fevereiro & $-43,4$ & $-43,2$ \\
Março & 16,7 & 16,9 \\
Abril & 72,8 & 73,1 \\
Maio & 130,7 & 131,0 \\
Junho & 223,7 & 223,9 \\
Julho & 134,5 & 134,7 \\
Agosto & 31,3 & 31,5 \\
Setembro & $-82,9$ & $-82,7$ \\
Outubro & $-129,4$ & $-129,1$ \\
Novembro & $-143,3$ & $-143,1$ \\
Dezembro & $-130,5$ & $-130,3$ \\
Soma & $-2,8$ & 0,0 \\
Excesso & $-0,229299342$ & \\
\hline
\end{tabular}

A Tabela 8 correspondente a representação dos valores de Precipitação Média por década ( $\mathrm{mm}$ ) evidencia que a segunda década (2001 a 2009) apresentou maior precipitação durante os meses de janeiro, fevereiro, março, abril, junho, julho, agosto e dezembro caracterizando uma possível anomalia climatológica de precipitação.

Tabela 8 - Precipitação média: diferença entre as médias mensais por década no período 1990 a 2009

\begin{tabular}{llccccccccccc}
\hline Década & Jan & Fev & Mar & Abr & Mai & Jun & Jul & Ago & Set & Out & Nov & Dez \\
\hline Primeira & 82 & 112 & 183 & 240 & 308 & 333 & 307 & 197 & 89 & 58 & 41 & 37 \\
Segunda & 115 & 147 & 219 & 277 & 306 & 485 & 335 & 240 & 46 & 46 & 40 & 68 \\
Diferença & 33 & 35 & 36 & 37 & -22 & 152 & 28 & 43 & -12 & -12 & -1 & 31
\end{tabular}

Figura 10 - Distribuição do número de ocorrências de Enchentes e/ou Inundações em 2010. Fonte de dados: Belo Horizonte (2012).

\section{Umidade Relativa do Ar}

O ar atmosférico sempre contém quantidade variável de vapor de água conforme a temperatura, região, estação, etc. Esse vapor, resultante da 
evaporação das águas dos mares, rios e lagos, sobretudo pela ação do calor solar, sobem na atmosfera e passa a fazer parte de sua composição. (COSTA, 2003).

Quando a Umidade Relativa do Ar encontra-se em níveis muito baixos, em regiões onde o inverno é quente e seco, a qualidade do ar piora com a concentração da poluição, provocando o aparecimento de distúrbios respiratórios devido ao ressecamento das mucosas. O percentual ideal está entre $50 \%$ a $80 \%$, porém, regiões como São Paulo podem atingir níveis baixos em torno de $12 \%$. Segundo a OMS (Organização Mundial de Saúde), a escala para a umidade relativa do ar é de atenção (20\% a $30 \%)$, alerta (12\% a $20 \%)$, e alerta máximo (abaixo de 12\%). LIMA, 2006

A existência de água na atmosfera e suas mudanças de fases desempenham papel fundamental em vários processos físicos naturais, como o transporte e a distribuição de calor na atmosfera, a evaporação e transpiração, a absorção de diversos comprimentos de onda da radiação solar e terrestre, bem como a formação vegetal predominante em uma determinada localidade (DELGADO, 2007).

A umidade relativa do ar é influenciada por alguns importantes controles climáticos como a temperatura, mesmo que não ocorra aumento ou diminuição em seu conteúdo de umidade. O uso de métodos de estimativa da umidade relativa do ar pode ser de grande utilidade, tanto ao setor agrícola como a qualquer outro. O conhecimento da umidade relativa do ar e suas interações com outros elementos meteorológicos ajudam no planejamento, manejo e gestão dos recursos hídricos (BELTRÃO, 2003).

A Figura 13 mostra o gráfico da média mensal de umidade relativa do ar com a linha de tendência para a série estudada. Por Recife ser uma cidade litorânea a umidade relativa do ar se mantém ao longo dos anos com valores próximos à média histórica.

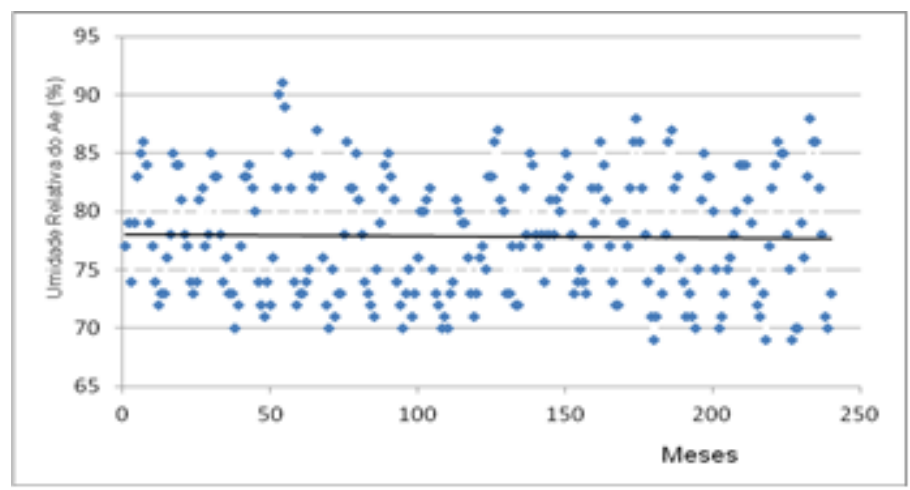

Figura 13 - Umidade relativa em Recife (1990-2009) e linha de tendência obtida por regressão linear

Nas Figura 14 e 15 pode-se observar os comportamentos da linha de tendência ao longo da série flutuando abaixo da média em quase todos os 
períodos. Apesar desses valores serem considerados altos em comparação a outras regiões do Brasil, para o Recife são considerados baixos por ser uma cidade litorânea. Com a queda da umidade relativa ocorre o aparecimento de.doenças respiratórias.

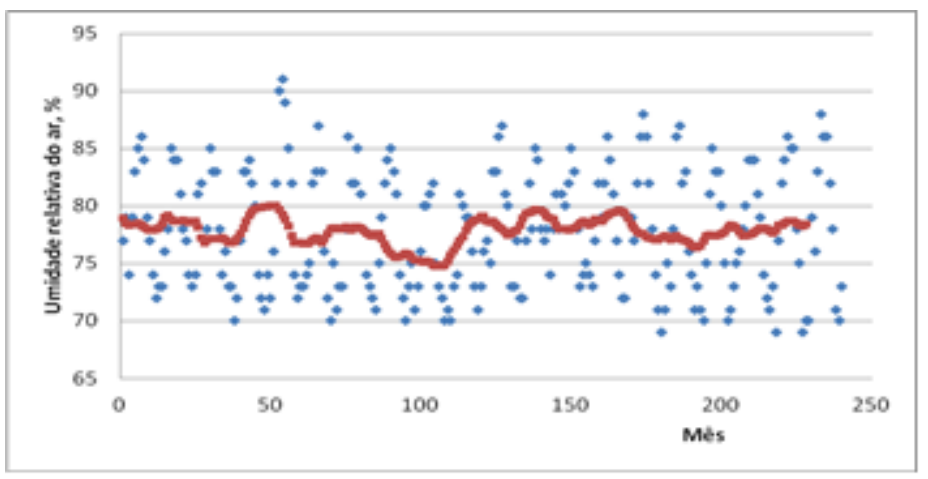

Figura 14 - Oscilações da umidade relativa do ar em Recife (1990-2009) e respectiva linha de tendência por média móvel simples

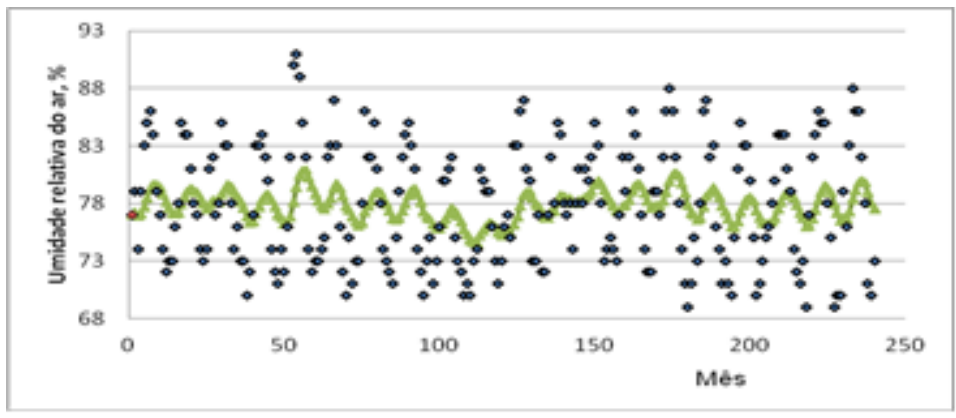

Figura 15 - Oscilações da umidade relativa do ar em Recife (1990-2009) e respectiva linha de tendência por média móvel exponencial

Observa-se na Tabela 9 que ocorreram valores negativos entre os meses de janeiro a março e setembro a dezembro com destaque para os meses de novembro com valor negativo de $(-5,4)$ e junho com valor positivo de $(7,1)$. 
Tabela 9 - Valores das Médias e Índices Sazonais da Umidade Relativa do Ar

\begin{tabular}{|c|c|c|}
\hline Mês & Média Sazonal & Índice Sazonal \\
\hline Janeiro & $-4,6$ & $-4,3$ \\
\hline Fevereiro & $-3,9$ & \\
\hline Março & $-1,6$ & $\begin{array}{l}-3,6 \\
-1,3\end{array}$ \\
\hline Abril & 2,1 & \\
\hline & & 2,4 \\
\hline Maio & 5,2 & 55 \\
\hline Junho & 6,8 & 7,1 \\
\hline Julho & 5,8 & 6,1 \\
\hline Agosto & 3,1 & \\
\hline Setembro & $-1,0$ & $\begin{array}{r}3,4 \\
-0,7\end{array}$ \\
\hline Outubro & $-4,2$ & $-3,9$ \\
\hline Novembro & $-5,7$ & $-5,4$ \\
\hline Dezembro & $-5,6$ & $-5,3$ \\
\hline Soma & $-3,5$ & 0,0 \\
\hline Excesso & 81 & \\
\hline
\end{tabular}

$\mathrm{Na}$ Tabela 10 observa-se que a umidade relativa do ar apresentou maiores percentuais na segunda década.

Tabela 10 - Umidade Relativa: diferença entre as médias mensais por década no período 1990 a 2009

\begin{tabular}{lllllllllllll}
\hline Década & Jan & Fev & Mar & Abr & Mai & Jun & Jul & Ago & Set & Out & Nov & Dez \\
\hline Primeira & 73, & 73, & 75, & 79, & 82, & 84, & 83, & 81, & 77, & 73, & 72, & 71, \\
& 4 & 8 & 8 & 3 & 9 & 2 & 7 & 4 & 2 & 8 & 9 & 2 \\
Segund & 74, & 75, & 77, & 88, & 83, & 85, & 84, & 81, & 69, & 73, & 71, & 73, \\
a & 1 & 2 & 1 & 4 & 8 & 6 & 4 & 1 & 5 & 7 & 8 & 0 \\
Diferenç & - & 1,4 & 1,3 & 9,1 & 0,9 & 1,4 & 0,7 & - & 7,7 & - & - & 0,9 \\
a & 0,7 & & & & & & & 0,3 & & 0,1 & 1,1 & \\
\hline
\end{tabular}

Na Tabela 11 a partir do ano 1996 até 2009 todos os valores da umidade relativa ficaram abaixo da média. Já as temperaturas média compensada, mínima e máxima apresentaram valores acima da média histórica. A 
precipitação apresentou durante 11 anos da série em estudo, valores abaixo da média histórica.

Tabela 11 - Médias anuais das variáveis meteorológicas da Cidade do Recife (1990 2009)

\begin{tabular}{cccccc}
\hline Ano & TCMM & TMáxMM & TMínMM & PMM & UR \\
\hline 1990 & 25,7 & 29,5 & 21,6 & 206,5 & 79 \\
1991 & 25,6 & 29,2 & 21,9 & 180,3 & 78 \\
1992 & 25,5 & 28,9 & 22,2 & 207,6 & 78 \\
1993 & 25,9 & 29,3 & 22,3 & 110,5 & 80 \\
1994 & 25,9 & 29,4 & 22,4 & 224,0 & 80 \\
1995 & 25,9 & 29,5 & 21,9 & 159,8 & 80 \\
1996 & 26,0 & 29,3 & 22,7 & 153,4 & 78 \\
1997 & 25,9 & 29,4 & 22,2 & 145,0 & 77 \\
1998 & 26,6 & 30,1 & 22,7 & 104,1 & 75 \\
1999 & 25,8 & 29,5 & 22,3 & 115,1 & 75 \\
2000 & 26,1 & 29,0 & 22,3 & 279,9 & 79 \\
2001 & 26,0 & 29,3 & 22,5 & 139,3 & 78 \\
2002 & 26,2 & 29,1 & 22,5 & 173,5 & 78 \\
2003 & 25,9 & 29,6 & 22,3 & 180,8 & 78 \\
2004 & 25,7 & 29,6 & 22,2 & 211,0 & 79 \\
2005 & 26,2 & 29,8 & 22,4 & 193,0 & 77 \\
2006 & 26,2 & 30,0 & 22,5 & 156,4 & 76 \\
2007 & 25,8 & 29,5 & 22,5 & 134,7 & 78 \\
2008 & 25,9 & 29,5 & 22,3 & 203,2 & 77 \\
2009 & 26,1 & 29,8 & 22,7 & 214,4 & 78 \\
\hline
\end{tabular}

\section{Estimativa de Erros para os Modelos}

A Tabela 12 apresenta os erros estimados para os modelos de previsão propostos neste trabalho. Entre os modelos de previsão aquele que mais se aproximou dos dados experimentais foi o obtido pela técnica estatística de média móvel exponencial. Com exceção do fenômeno da precipitação média mensal (PMM), as demais variáveis meteorológicas da cidade do Recife podem ser previstas com estimativas de erros percentuais médios conforme a referida tabela, a qual pode ser atualizada anualmente.

Tabela 12 - Erro percentual médio absoluto dos modelos propostos

\begin{tabular}{cccccc}
\hline \multirow{2}{*}{ Modelo da Análise } & \multirow{5}{*}{ TMCM } & TMáxMM & TMínMM & PMM & UR \\
\hline Regressão Linear & 3,9 & 3,7 & 4,3 & 68,2 & 5,6 \\
Média Móvel Linear & 3,9 & 3,6 & 3,5 & 66,0 & 5,5 \\
Média Móvel Exponencial & 3,6 & 3,4 & 3,3 & 63,5 & 5,2 \\
\hline
\end{tabular}

\section{Previsão para o Recife em 2010}

No modelo aditivo utilizado para detectar a influência da sazonalidade na previsão dos parâmetros meteorológicos para a Cidade do recife, existe influência desse sazonalidade caso os referidos índices sejam substancialmente diferentes de zero, o que parece serem os casos da maioria dos parâmetros 
abordados nesse trabalho. Dessa forma, com base nesses referidos índices, uma aplicação voltada para o objetivo desse trabalho seria a elaboração de uma tabela com previsões de parâmetros meteorológicos para a cidade do Recife em 2010, conforme a Tabela 13.

Tabela 13 - Previsões meteorológicas para a Cidade do Recife em 2010

\begin{tabular}{|c|c|c|c|c|c|}
\hline \multirow{2}{*}{ Mês } & \multicolumn{5}{|c|}{ Parâmetro Meteorológico } \\
\cline { 2 - 6 } & $\begin{array}{c}\text { TMCM } \\
\left({ }^{\circ} \mathrm{C}\right)\end{array}$ & $\begin{array}{c}\text { TMáxMM } \\
\left({ }^{\circ} \mathrm{C}\right)\end{array}$ & $\begin{array}{c}\text { TMínMM } \\
\left({ }^{\circ} \mathrm{C}\right)\end{array}$ & $\begin{array}{c}\text { PMM } \\
(\mathrm{mm} / \mathrm{ano})\end{array}$ & $\begin{array}{c}\text { UR } \\
(\%)\end{array}$ \\
\hline Janeiro & 27,13 & 27,79 & 23,41 & 81,02 & 72,11 \\
\hline Fevereiro & 27,37 & 27,92 & 23,29 & 142,73 & 73,05 \\
\hline Março & 27,38 & 28,78 & 22,98 & 198,97 & 75,30 \\
\hline Abril & 26,69 & 29,78 & 22,58 & 272,50 & 79,59 \\
\hline Maio & 25,93 & 30,48 & 21,88 & 351,87 & 83,85 \\
\hline Junho & 24,79 & 30,77 & 21,22 & 456,11 & 86,14 \\
\hline Julho & 24,12 & 30,92 & 21,96 & 381,44 & 85,79 \\
\hline Agosto & 24,98 & 30,82 & 21,60 & 282,12 & 83,66 \\
\hline Setembro & 24,88 & 30,66 & 22,33 & 150,23 & 79,10 \\
\hline Outubro & 25,81 & 30,16 & 22,89 & 81,94 & 75,32 \\
\hline Novembro & 26,55 & 29,53 & 23,11 & 51,57 & 72,60 \\
\hline Dezembro & 27,08 & 28,41 & 23,37 & 49,61 & 71,93 \\
\hline
\end{tabular}

\section{CONCLUSÃO}

As variáveis, temperatura média compensada, temperatura máxima média, temperatura mínima média e precipitação média, estudadas neste trabalho, apresentaram tendência positiva caracterizando para a cidade do Recife, uma discreta alteração climática, mais evidente na segunda década. Como exemplo, as temperaturas máximas registradas entre os anos de 2003 a 2009, nos meses novembro, dezembro, janeiro, fevereiro, março e abril, variaram entre $30^{\circ} \mathrm{C}$ e $31,9^{\circ} \mathrm{C}$, valores estes considerados acima da média climatológica, porém é importante ressaltar que os valores de temperatura considerados altos ocorreram em dias isolados não tendo sido registrados valores que se estenderam ao longo de um ou mais meses. A precipitação acumulada foi muito maior na segunda década mas, apesar disso, ficou bem abaixo dos registros observados entre os anos 1960 a 1990. Durante os 19 anos do período escolhido para a presente pesquisa, o evento climático El Niño ocorreu 9 vezes fazendo com que boa parte da comunidade científica atribua a este fenômeno a provável responsabilidade das anomalias climáticas observadas nas últimas décadas.

A temperatura média compensada mensal (TMCM) apresentou elevação de 0,2 a $0,3^{\circ} \mathrm{C}$ para os meses de novembro e dezembro respectivamente, caracterizando um aquecimento da segunda década em relação à primeira. Verificou-se uma anomalia da TMCM, através dos índices sazonais obtidos para o mês de agosto $\left(-1,77^{\circ} \mathrm{C}\right)$ abaixo da média e para o mês de fevereiro com valor de $\left(1,30^{\circ} \mathrm{C}\right)$ acima da média. A temperatura máxima média mensal apresentou elevação de $0,3^{\circ} \mathrm{C}$ a $0,5^{\circ} \mathrm{C}$ nos meses de agosto e novembro, caracterizando um aumento da temperatura da região em estudo, principalmente para a segunda década.

Valores positivos de temperatura mínima foram registrados entre os meses de maio a dezembro da última década com aumento de 0,4 a $0,5^{\circ} \mathrm{C}$ para 
os meses de novembro e dezembro respectivamente. Observou-se grande variabilidade intra sazonal de precipitação com destaque para o mês de junho dos anos 2000 com valores médios de 562,9mm, 2002 com 583,5mm, 2004 com 537,3mm, 2005 com 709,0mm. O volume total de precipitação acumulada da primeira década (1990 a 1999) foi de $15.039 \mathrm{~mm}$, bem menor do que o volume observado na segunda década (2000 a 2009) de $24.164,1 \mathrm{~mm}$. É provável que o maior volume registrado na segunda década caracterize uma anomalia de precipitação para a cidade do Recife. O modelo aditivo para cálculo dos índices sazonais apresentou habilidade na previsão das variáveis estudadas e permitiu verificar a influência da sazonalidade em virtude de os índices sazonais terem sido substancialmente diferentes de zero. Em virtude da cidade do Recife ser de localização litorânea a umidade relativa do ar flutuou próximo dos $80 \%$, mas não foram encontradas alterações importantes ao longo desta pesquisa.

Agradecimentos: Agradeço a CAPES (Coordenação de Aperfeiçoamento de Pessoal de Nível Superior) pela concessão da bolsa durante todo o período de realização (2009/2011) do meu mestrado.

\section{REFERÊNCIAS BIBLIOGRÁFICAS}

ALVES, J. M. B.; SOUZA, R. O.; CAMPOS, J. N. B. Previsão da anomalia de temperatura da superfície do mar (tsm) no atlântico tropical, com a equação da difusão de temperatura. Revista Climanalise, ano 03, n. 01, 2005.

BERTALANFFY, Ludwig Von. Teoria General de los Sistemas, 10a ed., México: FCE, 1995.

BLOCH, S. C. EXCEL para Engenheiros e Cientistas. Rio de Janeiro: LTC, 2004.

BOX, G E P. Time Series Analysis: Forecasting and Control. 3. ed. Englewood Cliffs:

Prentice Hall, 1994. 598p.

BEltrÃo, N. E. M.; ARAúJO, A E; BENASSI, A C; Zoneamento e época de plantio para o algodoeiro no norte do Espírito Santo. Revista Brasileira de Engenharia Agrícola e Ambiental, Campina Grande, v.7, n.1, p.99-105, 2003.

BEZERRA, A. C.; CAVALCANTI, E. P. Energia estática sobre o Nordeste do Brasil relacionada com a temperatura da superfície do mar. Revista Brasileira de Meteorologia, São José dos Campos, v. 23, n. 2, p. 239-263, 2008.

COSTA, E V. Medidas da Umidade relativa do Ar em um ambiente fechado. Revista Brasileira de Ensino de Física, vol. 25, no. 3, Setembro, 2003.

DELGADO, R. C.; SEDIYAMA, G. C.; ANDRADE, R G. Modelos para prognósticos da umidade relativa do ar em escala horária no município de Muriaé, MG. Anais I Seminário de Recursos Hídricos da Bacia Hidrográfica do Paraíba do Sul: o Eucalipto e o Ciclo Hidrológico, Taubaté, Brasil, 07-09 novembro 2007, IPABHi, p. 295-300.

DIGGLE P. J. Time series: a biostatistical introduction. Oxford: Oxford University Press, 1992. 
FILHO, R. A. P., SILVA, J. C. C., Gomes, S. B. Sistemas Integrados de Tratamento e usos de Águas Residuárias na América Latina: Realidade e Potencial. 54 p, Centro Pan-Americano de Engenharia Sanitária e Ciências do Ambiente. Fortaleza. 2002.

HASTENRATH, S. Interannual Variability and Annual Cycle: Mechanisms of Circulation and Climate in the Tropical Atlantic Sector. Mon. Wea. Rev., 112, 1097-1107. 1984.

KOUSKY,V.E., CAVALCANTI, I.F.A., GAN, M.A., 1983. Contrasts between wet an dry periods within the 1981 rainy season in Northeast Brazil. INPE - 2728 PRE/310.

LOMBARDO, M. A. Ilha de calor nas metrópoles: o exemplo de São Paulo, São Paulo-SP: Editora Hucitec, 1985. 244p.

McCULLOUGH, B.D.; HEISER, D. A. On the accuracy of statistical procedures in Microsoft Excel 2007, Computational Statistics and Data Analysis, 52, 45704578. 2008.

MOREIRA, C. M. Estratégias de simulação em supermercados: avaliação por meio de simulação. 2001. 148 f. Dissertação (Mestrado em Engenharia de Produção) - Universidade Federal de Santa Catarina, Florianópolis, 2001.

MORETTIN, P. A., TOLOI, C. M. C. Análise de séries temporais. São Paulo: Edgard Blücher, 2004. 535p.

MOURA, B A G; ARAGÃO, J O R; LACERDA, F F; PASSAVANTE, J Z O. Relação entre a Precipitação no setor leste do Nordeste do Brasil e a temperatura de superfície nos Oceanos Atlântico (área do dipolo) e Pacífico. Revista Brasileira de Engenharia Agrícola e Ambiental, v.4, n.2, p.247 - 251. 2000.

MUNN, R.E. Descriptive Micrometeorology. Advances in Geophysics. New York: Academic Press, 1996, v. I. 199p.

SILVA, F D S; CORREIA, M F; ARAGÃO, M R S; SILVA, J M. Convecção linearmente organizada na área de Petrolina, semi-árido do Nordeste do Brasil: aspectos em meso e grande escala. Ver. Brás. Meteorol. Vol.23, n³. São Paulo. 2008.

TSONIS, E. S.; Elsner, T. K. Chaos, strage atractors and weather. Bulletin of the American Meteorological Society, Vol. 70, pg 14-23, 1999.

UVO, C. B.; REPELLI, C. A.; ZEBIAK, S. E.; KUSHNIR, Y. The Relationships between Tropical Pacific and Atlantic SST and Northeast Brazil Monthly Precipitation. J. Climate, 11, 551-562. 1998. 